\title{
Iron Levels Increased in Serum from Gestational Diabetes Mellitus Mothers in Coastal Area of Andhra Pradesh
}

\author{
Prasad DKV ${ }^{1}$, Sheela $\mathrm{P}^{2}$, Kumar $\mathrm{AN}^{3 *}$, Kumar $\mathrm{NL}^{4}$, Deedi $\mathrm{MK}^{4}$ and Madhulatha $\mathrm{D}^{2}$
}

${ }^{1}$ Institute of Genetics \& Hospital for Genetic Diseases, Dr NTRUHS, India

${ }^{2}$ Institute of Genetics \& Hospital for Genetic Diseases, Osmania University, India

${ }^{3}$ Department of Biochemistry, Narayana Medical College, Dr NTRUHS, India

${ }^{4}$ Department of Biochemistry, GSL Medical College, India

\begin{abstract}
Background: Gestational diabetes mellitus (GDM) has been observed to be associated with increased perinatal morbidity and mortality. GDM affects approximately $7 \%$ of all pregnancies. The objective of the present study was to establish correlation of serum iron, phosphorous and hemoglobin levels in women with carbohydrate tolerance in gestational diabetes mellitus and to find out its association with gestational diabetes mellitus (GDM)
\end{abstract}

Methods: The study involved screening of 100 pregnant women with gestational period of $24-28$ weeks, for carbohydrate tolerance and prevalence of gestational diabetes mellitus. We estimated fasting glucose, post load glucose, serum iron, serum phosphorous, and hemoglobin in all 100 pregnant women selected for this study. The study was carried out in the department of OBG in collaboration with department of biochemistry.

Results: In the present study, prevalence of Gestational Diabetes Mellitus is $8 \%$. Both fasting and post serum glucose levels are significantly high in cases of Gestational Diabetes Mellitus. We observed increase in serum iron level for gestational diabetes mellitus mothers and is associated with carbohydrate tolerance. However, there was no correlation observed with phosphorous and hemoglobin levels in GDM mothers.

Conclusion: Present study showed elevated serum iron levels correlates with the development of Gestationa Diabetes Mellitus. Serum phosphorous and hemoglobin concentrations have not shown any significant variation.

Keywords: Gestational diabetes mellitus; Pregnancy; Serum iron; Serum phosphorous; Carbohydrate tolerance

\section{Introduction}

Gestational diabetes mellitus (GDM) is a disturbance in glucose metabolism, which is diagnosed during pregnancy and affects pregnant women [1]. The incidence of gestational diabetes has been increasing the last 20 years [2]. The longitudinal changes in carbohydrate metabolism during gestation are integral to a successful pregnancy outcome for both mother and fetus. Therefore, prevention of any disease particularly non-communicable diseases includes four steps that include primary prevention, post primary prevention, secondary prevention and tertiary prevention [3]. The steps taken after diagnosing some form of abnormal glucose tolerance like impaired fasting glucose (IFG) or impaired glucose tolerance (IGT) is called post primary prevention.

There are two components for the development of any disease, the genetic and the environmental factors. Of the two, there are evidences to establish the fact that the intra uterine environment plays a vital role in the development of diabetes. Intrauterine exposure to hyperglycemia during the critical period of fetal development programs the development of pancreas [4] relatively and affects insulin secretion function. Further maternal hyperglycemia has a direct effect on the fetal pancreas and is associated with the increased susceptibility to future diabetes in the infant. Women with a history of gestational diabetes mellitus as well as their children are at increased risk of future diabetes, predominantly type II diabetes [5].

During pregnancy, there is a significant alteration in glucose homeostasis secondary to the complex hormonal changes and increased metabolic demands of gravid uterus, its contents, and the mother [6]. The rise in the hormones includes estrogen, progesterone [7], human placental lactogen and cortisol that alters this metabolism is largely responsible for the altered homeostasis [8]. Gestational diabetes mellitus is the most common metabolic abnormality of carbohydrate metabolism of pregnancy occurring in $1-14 \%$ of the patients depends a population described and criteria used for diagnosis of gestational diabetes mellitus is defined as carbohydrate intolerance of any degree with onset or first recognition during pregnancy.

Diagnosis of gestational diabetes mellitus is important to identify both infants at risk of adverse outcomes and women at risk of subsequent development of diabetes. In addition to fetal demise [9], gestational diabetes mellitus has been linked to the complications of large for gestational age, macrosomia, birth trauma such as increased maternal lacerations and neonatal shoulder dystocia, increased need for operative interference and neonatal metabolic disorders such as hypoglycemia, hyperbilirubinemia and disordered calcium balance [10]. The occurrence of gestational diabetes mellitus may go unrecognized throughout pregnancy unless complications arise and some of these may occur very late. Because gestational diabetes mellitus is associated with adverse effects on the pregnancy and a significant number of patients subsequently develop overt diabetes, it is important to screen for the condition.

*Corresponding author: Amar Nagesh Kumar, Department of Biochemistry, Narayana Medical College, Dr NTRUHS, India, E-mail: amarnageshkumar@gmail.com

Received May 06, 2013; Accepted June 16, 2013; Published June 20, 2013

Citation: Prasad DKV, Sheela P, Kumar AN, Kumar NL, Deedi MK, et al. (2013) Iron Levels Increased in Serum from Gestational Diabetes Mellitus Mothers in Coastal Area of Andhra Pradesh. J Diabetes Metab 4: 269. doi:10.4172/21556156.1000269

Copyright: (c) 2013 Prasad DKV, et al. This is an open-access article distributed under the terms of the Creative Commons Attribution License, which permits unrestricted use, distribution, and reproduction in any medium, provided the original author and source are credited. 
An increased iron requirement and increased red blood cell production is required when the body is going through changes such as growth spurts in children and adolescents, or during pregnancy and lactation. Transitional metals especially iron, which are particularly abundant in the placenta, are important in the production of free radicals. Antioxidants as well as avoidance of iron excess ameliorate maternal and early fetal damage $[9,10]$.

Most of the body's phosphorus is combined with calcium in the bones, but about $15 \%$ exists as phosphate $\left(\mathrm{PO}^{4-}\right)$ ions - in the blood and other soft tissues and body fluids. Dietary phosphorus is efficiently absorbed, so a low phosphate level caused by dietary deficiency is unlikely in those on a normal diet unless the person has a malabsorption syndrome (inadequate absorption of nutrients in the intestinal tract). Phosphate levels are controlled by parathyroid hormone and 1,25-dihydroxy vitamin $\mathrm{D}$. The 1,25-dihydroxy vitamin $\mathrm{D}$ increases absorption of calcium and phosphate in the intestines. Parathyroid hormone $[11,12]$ increases calcium and $\mathrm{PO}^{4-}$ release from bone, decreases loss of calcium and increases loss of $\mathrm{PO}^{4-}$ in the urine and Increases conversion of 25-hydroxy vitamin D to 1,25 - dihydroxy vitamin $\mathrm{D}$ in the kidneys.

\section{Material and Methods}

In the present study, we have screened 100 antenatal cases with gestational period of $24-28$ weeks to find out the incidence of gestational diabetes mellitus in coastal area of Andhra Pradesh. We tried to correlate serum iron, serum phosphorous, hemoglobin levels with Carbohydrate intolerance in gestational diabetes mothers. Carbohydrate tolerance is measured by assaying Mean fasting glucose and Mean post load glucose.

About $5 \mathrm{ml}$ of venous blood was collected from 100 antenatal cases in plain and EDTA containers. Whole blood collected in EDTA tubes is used for hemoglobin analysis. Blood collected in plain tubes is centrifuged at $3000 \mathrm{rpm}$ for 5 minutes to separate serum. Separated serum was transferred to a fresh vial and is used for the estimation of Iron, Phosphorous, Glucose. The case history and the complete clinical examination findings of the patients were recorded and informed consent was taken from all the subjects who are enrolled for study.

Glucose, Iron, Phosphorous are estimated by using commercially available kits and analyzed on fully automated biochemistry analyzer. Serum glucose is estimated by Glucose oxidase and Peroxidase method using Human reagent kit. Serum iron is estimated by Chromazurol B (CAB) method using Human kit. Phosphomolybdate UV- End - Point method using Human kit, estimates serum phosphorous. All these parameters are estimated on Huma Star 600 fully automated biochemistry analyzer. Hemoglobin is estimated by using Cyanmethemoglobin colorimetric method.

The present study was done to know the incidence of glucose intolerance in pregnant women and to evaluate the relation with serum iron, serum phosphorous and hemoglobin in 100 pregnant women between 24-28 weeks of gestational period. Oral glucose tolerance test (OGTT) with $75 \mathrm{~g}$ glucose without regard to recent meal status was done for all the 100 antenatal cases. In the same cases, serum iron and serum phosphorous were also measured $[13,14]$. The criteria for the diagnosis of gestational diabetes mellitus is according to the WHO recommendations i.e, fasting blood sugar $\geq 99 \mathrm{mg} / \mathrm{dL}$, post glucose load blood sugar value $\geq 144 \mathrm{mg} / \mathrm{dL}$.

\section{Results and Discussion}

In present study, out of 100 antenatal study subjects screened we find eight women with carbohydrate tolerance. Therefore, the prevalence of gestational diabetes mellitus was $8 \%$, which is comparable to the world wide prevalence. Out of 100 Pregnant women screened 92 pregnant women are with normal glucose tolerance $(n=92)$ and eight pregnant women are found with abnormal glucose tolerance. Pregnant women with abnormal glucose tolerance are compared with normal glucose tolerance pregnant women. Student ' $t$ ' test is used for calculation for all the parameters. We found $\mathrm{p}$ value $<0.001$ which is statistically significant (Table 1).

The frequency of gestational diabetes mellitus depends on both the population studied and the diagnostic criteria used resulting in the range of prevalence between $1 \%$ and $14 \%$ the prevalence of gestational diabetes tends to be higher in populations with high rate of type 2 diabetes $[13,14]$.

Screening of women between 24-28 weeks gestation with serum glucose levels obtained after $120 \mathrm{~min}$. following $75 \mathrm{~g}$ glucose load test administered at any time of the day without regard to the time since the last meal has become a well validated and widely applied screening procedure. A value of $140 \mathrm{mg} / \mathrm{dL}$ or higher identifies $80 \%$ women with gestational diabetes mellitus, and a value of $130 \mathrm{mg} / \mathrm{dL}$ or higher increases the sensitivity to $90 \%$. Both fasting serum glucose and post load serum glucose levels are significantly higher in cases with abnormal glucose tolerance when compared with cases of normal glucose tolerance $(\mathrm{p}<0.0001)$.

Serum iron concentration is significantly higher in cases with abnormal glucose tolerance when compared with cases of normal glucose tolerance. It is well established that people with haemochromatosis, a genetic condition that causes extremely high levels of iron levels in the body are at increased risk for developing diabetes. But a new study suggests even a moderately elevated iron levels may be associated with diabetes $[15,16]$.

Recent studies showed pregnant women who developed gestational diabetes mellitus had higher concentrations of serum Ferritin than women who did not develop gestational diabetes mellitus. But a new study suggests even a moderately elevated iron levels may be associated with diabetes $[15,16]$.

In another prospective, study done in University of Hong Kong to determine whether non-anaemic women with gestational diabetes

\begin{tabular}{|c|c|c|}
\hline Parameter & Normal glucose tolerance (Mean S.D) $(\mathbf{n = 9 2 )}$ & Abnormal glucose tolerance (Mean \pm S.D) (n=8) \\
\hline Fasting serum glucose $(\mathrm{mg} / \mathrm{dL})$ & $76.78 \pm 9.88$ & $107.25 \pm 13.59$ \\
\hline Post serum glucose $(\mathrm{mg} / \mathrm{dL})$ & $102.22 \pm 24.43$ & $147 \pm 4.76$ \\
\hline Serum iron $(\mu \mathrm{g} / \mathrm{dL})$ & $111.35 \pm 53.08$ & $<.001^{*}$ \\
\hline Serum phosphorous $(\mathrm{mg} / \mathrm{dL})$ & $3.367 \pm 0.58$ & $<.001^{*}$ \\
\hline Hemoglobin $(\mathrm{Gm} \%)$ & $9.776 \pm 1.41$ & Not significant \\
\hline
\end{tabular}

*significant $p$ Value $<0.0001$

Table 1: Showing all the parameters measured and compared among pregnant women with normal glucose tolerance $(n=92)$ and abnormal glucose tolerance $(n=8)$. 
Citation: Prasad DKV, Sheela P, Kumar AN, Kumar NL, Deedi MK, et al. (2013) Iron Levels Increased in Serum from Gestational Diabetes Mellitus Mothers in Coastal Area of Andhra Pradesh. J Diabetes Metab 4: 269. doi:10.4172/2155-6156.1000269

mellitus have evidence of increased iron stores. The concentrations of serum ferritin, iron, transferrin saturation and postnatal haemoglobin were significantly higher in gestational diabetes mellitus patients, but there was no difference in the weight, body mass index, third trimester haemoglobin and they concluded that there was an association between increased iron stores and glucose intolerance at the third trimester in non-anaemic women [16]. The role of iron excess in the pathogenesis of gestational diabetes mellitus needs to be examined.

Another prospective study in New Jersey, showed pregnant women who developed gestational diabetes mellitus had a higher concentration of serum ferritin than women who did not develop gestational diabetes mellitus [10,16,17]. Recently, a case control study in Chinese women was done to examine the relationship between high hemoglobin concentration and occurrence of gestational diabetes mellitus. Women with body mass index $>26 \mathrm{~kg} / \mathrm{m}^{2}$ has shown that who developed World Health Organization category of impaired glucose tolerance, with the 2-hr glucose values of the $75 \mathrm{~g}$ OGTT between $144 \mathrm{mg}$ to 196 $\mathrm{mg} / \mathrm{dL}$ (WHO, 1980) during pregnancy has significantly increased hemoglobin concentration compared with body mass index matched controls $[14,18,19]$

In our present study, the hemoglobin concentration was also estimated but no significance was noted in the concentration of hemoglobin when compared with normal and abnormal glucose tolerance cases. Women with BMI $>26 \mathrm{~kg} / \mathrm{m}^{2}$ has shown that who developed WHO category of impaired glucose tolerance, with the 2-hr glucose values of the $75 \mathrm{~g}$ OGTT between $144 \mathrm{mg}$ to $196 \mathrm{mg} / \mathrm{dL}$. During pregnancy has significantly increased hemoglobin concentration compared with BMI matched controls $[16,17,20]$. There is no significant change in Serum phosphorous and hemoglobin concentrations in both the groups.

\section{Conclusion}

In the present study, the prevalence of Gestational Diabetes Mellitus is $8 \%$ in cases attending the antenatal clinic in our teaching hospital. Both fasting and post load serum glucose levels are significantly high in cases of Gestational Diabetes Mellitus. Serum iron is significantly high in cases of Gestational Diabetes Mellitus. Our study showed elevated serum iron levels correlates with the development of Gestational Diabetes Mellitus. Serum phosphorous and hemoglobin concentrations have not shown any significant variation.

\section{Acknowledgements}

Authors expressed their sincere gratitude to Dr.Y.N.Rao, Dr N Ammanna Pantulu, GSL Medical College, Rajahumandry, East Godavari district, Andhra Pradesh, India for their constant support and encouragement to accomplish this project.

\section{References}

1. American Diabetes Association (2012) Diagnosis and classification of diabetes mellitus. Diabetes Care 35 Suppl 1: S64-71.

2. Ferrara A (2007) Increasing prevalence of gestational diabetes mellitus: a public health perspective. Diabetes Care 30 Suppl 2: S141-146.

3. de Sereday MS, Damiano MM, González CD, Bennett PH (2003) Diagnostic criteria for gestational diabetes in relation to pregnancy outcome. J Diabetes Complications 17: 115-119.
4. Buchanan TA, Xiang A, Kjos SL, Lee WP, Trigo E, et al. (1998) Gestationa diabetes: antepartum characteristics that predict postpartum glucose intolerance and type 2 diabetes in Latino women. Diabetes 47: 1302-1310.

5. Handwerger S (1991) Clinical counterpoint: the physiology of placental lactogen in human pregnancy. Endocr Rev 12: 329-336.

6. Metzger BE, Coustan DR (1998) Summary and recommendations of the Fourth International Workshop-Conference on Gestational Diabetes Mellitus. The Organizing Committee. Diabetes Care 21 Suppl 2: B161-167.

7. Lind T (1979) Metabolic changes in pregnancy relevant to diabetes mellitus Postgrad Med J 55: 353-357.

8. Idonije BO, Oluba OM, Festus OO, Otamere HO (2011) Serum Chromium and Iron Levels in Pregnant Women Attending a Nigerian Teaching Hospital in Relation to Gestational Diabetes. Asian J Pharm Biol Res 1: 158-162.

9. Afkhami-Ardekani M, Rashidi M (2009) Iron status in women with and without gestational diabetes mellitus. J Diabetes Complications 23: 194-198.

10. Carriaga MT, Skikne BS, Finley B, Cutler B, Cook JD (1991) Serum transferrin receptor for the detection of iron deficiency in pregnancy. Am J Clin Nutr 54 1077-1081.

11. Sebastian A, Hernandez RE, Portale AA, Colman J, Tatsuno J, et al. (1990) Dietary potassium influences kidney maintenance of serum phosphorus concentration. Kidney Int 37: 1341-1349.

12. Mayne PD, Kovar IZ (1991) Calcium and phosphorus metabolism in the premature infant. Ann Clin Biochem 28 : 131-142.

13. Soubasi V, Petridou S, Sarafidis K, Tsantali Ch, Diamanti E, et al. (2010) Association of increased maternal Ferritin levels with gestational diabetes and intra uterine growth retardation. Diabetes Metab 36: 58-63.

14. de Veciana M, Major CA, Morgan MA, Asrat T, Toohey JS, et al. (1995) Postprandial versus preprandial blood glucose monitoring in women with gestational diabetes mellitus requiring insulin therapy. N Engl J Med 333: 1237 1241.

15. Buchanan TA, Xiang AH, Peters RK, Kjos SL, Berkowitz K, et al. (2000) Response of pancreatic beta-cells to improved insulin sensitivity in women at high risk for type 2 diabetes. Diabetes 49: 782-788.

16. Helin A, Kinnunen TI, Raitanen J, Ahonen S, Virtanen SM, et al. (2012) Iron intake, haemoglobin and risk of gestational diabetes: a prospective cohort study. BMJ Open 2.

17. Lao TT, Ho LF (2000) Impaired glucose tolerance and pregnancy outcome in Chinese women with high body mass index. Hum Reprod 15: 1826-1829.

18. Jiang R, Ma J, Ascherio A, Stampfer MJ, Willett WC, et al. (2004) Dietary iron intake and blood donations in relation to risk of type 2 diabetes in men: a prospective cohort study. Am J Clin Nutr 79: 70-75.

19. Lao TT, Chan PL, Tam KF (2001) Gestational diabetes mellitus in the last trimester - a feature of maternal iron excess? Diabet Med 18: 218-223.

20. Chen X, Scholl TO, Stein TP (2006) Association of elevated serum ferritin levels and the risk of gestational diabetes mellitus in pregnant women: The Camden study. Diabetes Care 29: 1077-1082. 